\title{
Effects of endurance training on the isocapnic buffering and hypocapnic hyperventilation phases in professional cyclists
}

\author{
José L Chicharro, Jesús Hoyos, Alejandro Lucía
}

\begin{abstract}
Objectives-To evaluate the changes produced in both the isocapnic buffering and hypocapnic hyperventilation (HHV) phases of professional cyclists $(n=11)$ in response to endurance training, and to compare the results with those of amateur cyclists $(\mathrm{n}=11)$.

Methods-Each professional cyclist performed three laboratory exercise tests to exhaustion during the active rest (autumn: November), precompetition (winter: January), and competition (spring: May) periods of the sports season. Amateur cyclists only performed one exercise test during the competition period. The isocapnic buffering and $\mathrm{HHV}$ ranges were calculated during each test and defined as $\mathrm{Vo}_{2}$ and power output (W).

Results-No significant differences were found in the isocapnic buffering range in each of the periods of the sports season in professional cyclists. In contrast, there was a significant reduction in the HHV range (expressed in $W$ ) during both the competition $(p<0.01)$ and precompetition $(p<0.05)$ periods compared with the rest period. On the other hand, a longer HHV range $(p<0.01)$ was observed in amateur cyclists than in professional cyclists (whether this was expressed in terms of $\mathrm{Vo}_{2}$ or $\mathrm{W}$ ).

Conclusions-No change is observed in the isocapnic buffering range of professional cyclists throughout a sports season despite a considerable increase in training loads and a significant reduction in $\mathrm{HHV}$ range expressed in terms of power output. (Br F Sports Med 2000;34:450-455)
\end{abstract}

Keywords: training; cycling; isocapnic buffering; hypocapnic hyperventilation

Although high maximal oxygen uptake $\left(\mathrm{VO}_{2} \mathrm{MAX}\right)$ is required for professional cyclists to perform well, other physiological characteristics, such as the ability to maintain high percentages - that is, $90 \%$ - of $\mathrm{Vo}_{2} \mathrm{MAX}$ during prolonged periods ( $>30-40$ minutes), play a more relevant role in successful endurance cycling. ${ }^{1-4}$ Moreover, several authors have shown that the physical performance of runners, ${ }^{5}$ swimmers, ${ }^{6}$ and cyclists ${ }^{7}$ may show significant improvement despite no change in $\mathrm{VO}_{2}$ MAX. Recently, we reported no significant differences in the $\mathrm{VO}_{2} \mathrm{MAX}$ values of professional and amateur cyclists. ${ }^{2}$ Thus it seems that, after a particular level of adaptation to exercise, improvement in performance is unrelated to changes in $\mathrm{VO}_{2} \mathrm{MAX}$.

On the other hand, the first increase in blood lactate concentration (lactate threshold) with no associated decrease in $\mathrm{pH}$ is the first sign of the onset of buffering at increasing exercise intensities. ${ }^{8}$ The lactic acid produced in exercising muscles is predominantly buffered by $\mathrm{HCO}_{3}{ }^{-9} .{ }^{9}$ As a result, three physiological gas exchange phases can be identified during rapid incremental exercise testing ${ }^{10}$ : phase I, in which $\mathrm{CO}_{2}$ production $\left(\mathrm{VCO}_{2}\right)$ is mainly from oxidative metabolism; phase II ("isocapnic buffering"), during which pulmonary ventilation (VE) increases in response to the rise in $\mathrm{VCO}_{2}$ from buffering, with regulation of arterial partial pressure of $\mathrm{CO}_{2}\left(\mathrm{PaCO}_{2}\right)$; and phase III, in which respiratory compensation for metabolic acidosis with lowering of $\mathrm{PaCO}_{2}$ ("hypocapnic hyperventilation" or HHV) occurs. The points that limit these three phases are called the ventilatory threshold (VT; between phases I and II) and the respiratory compensation point (RCP; between phases II and III). The onset of respiratory compensation of exercise acidosis, when exercise intensity is further increased, marks the final transition from the buffering phase to exercise acidosis. The high workloads at which both VT and RCP occur in professional cyclists $\left(\sim 65 \%\right.$ and $\sim 90 \%$ of $\mathrm{VO}_{2} \mathrm{MAX}$ respectively) and the appreciable difference between these values and those recorded in amateur cyclists (VT $\sim 60 \%$ of $\mathrm{VO}_{2} \mathrm{MAX}$ and RCP $\sim 80 \%$ of $\mathrm{VO}_{2} \mathrm{MAX}$ respectively $)^{2}$ suggest that such submaximal variables may be important indicators of performance in endurance events such as professional road races. The $\% \mathrm{VO}_{2} \mathrm{MAX}$ at which RCP occurs may determine the cyclist's potential for prolonged physical activity. ${ }^{12} 11{ }^{12}$ In turn, changes in VT and RCP with endurance training condition the duration of the isocapnic buffering and HHV phases, reflecting the body's general buffering capacity.

Surprisingly little research ${ }^{81314}$ has focused on the phases of isocapnic buffering and HHV. When these authors ${ }^{14}$ investigated the effects of training on the range of isocapnic buffering and HHV, they observed that the increase in the RCP is larger than that of VT after high intensity endurance training in runners. To our knowledge, however, no investigation has attempted to evaluate the possible changes produced in the isocapnic and HHV phases of professional cyclists in response to endurance training during a sports season. The aim of this longitudinal study was to analyse these changes 
Table 1 Physical characteristics of the amateur and professional cyclists studied (competition period)

\begin{tabular}{lll}
\hline & Amateur $(n=11)$ & Professional $(n=11)$ \\
\hline Age (years) & $23(3)$ & $24(2)$ \\
Stature (cm) & $176.4(4.2)$ & $179.7(6.2)$ \\
Mass (kg) & $67.1(6.7)$ & $68.2(4.8)$ \\
BMI & $21.6(1.5)$ & $22.2(1.6)$
\end{tabular}

All values are expressed as means (SD). There were no significant differences between means. BMI, body mass index.

and to compare the results obtained in professional cyclists with corresponding data for amateur well trained cyclists.

\section{Methods}

SUBJECTS

Eleven elite (amateur category) male road cyclists and 11 professional male road cyclists participated in this study. A previous physical examination (including electrocardiographic (ECG) and echocardiographic evaluation within the previous months) ensured that each participant was in good health. Table 1 shows the age and physical characteristics of the subjects.

The amateur cyclists had competition experience of 3 (1) years (mean (SD)) in the "sub23-elite" category and had covered an average of about $24000 \mathrm{~km}$ (including training and competition) during the previous season. The professional cyclists had professional competition experience of 4 (2) years and, over the last season, had covered about $32000 \mathrm{~km}$ (including training and competition). Most of them had completed several three week stage races - for example, Vuelta a España, Tour de France-and several had won international Cycling Union races.

Training volume for the professional cyclists was expressed as the average number of kilometres cycled a week during each of the three periods of the sports season: active rest (autumn: November), precompetition (winter: January), and competition (spring: May). The training volume of the amateur cyclists (average number of kilometres cycled a week) during the competition period was also recorded. All the subjects wore a heart rate telemeter (Polar Vantage NV; Polar Electro, Oy, Finland) during training sessions, which allows continuous recording of heart rate for later analysis. The intensity of training was determined by estimating for each subject the percentage of his weekly training performed at a heart rate corresponding to an exercise intensity below VT (low intensity training), between VT and RCP (moderate intensity training), and above RCP (high intensity training). Figure 1 shows the training characteristics of the two groups. In brief, both training volume and intensity - that is, percentage of high intensity training - of the professional cyclists increased in the following order: rest<precompetition<competition. Although training volume was greater in professional cyclists than in amateur cyclists during competition ( $800 v 500 \mathrm{~km} /$ week respectively), relative training intensity was comparable in the
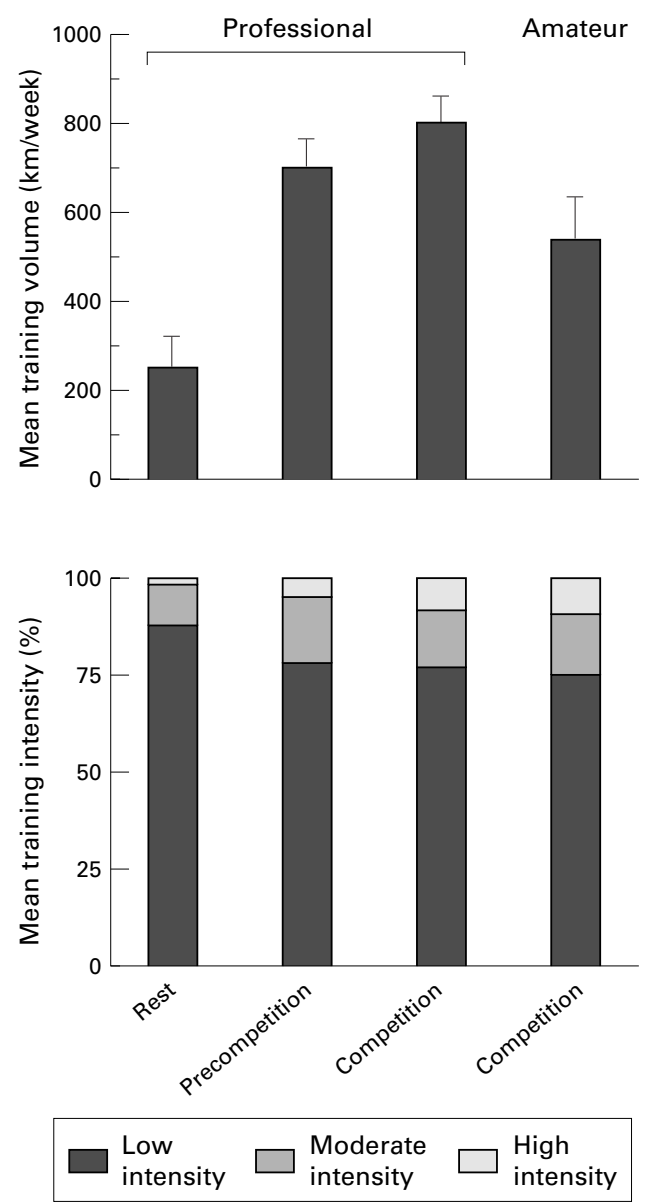

Figure 1 Training characteristics of the professional and amateur cyclists. Training volume is expressed as mean (SD).

two groups during this period-that is, high intensity training accounted for about $10 \%$ of total weekly training.

STUDY PROTOCOL

Informed consent was obtained from each participant in accordance with the guidelines of the Complutense University. Each professional cyclist reported to the laboratory three times during the study to perform exercise tests corresponding to the rest (November), precompetition (January), and competition periods (May) of the sports season. Amateur cyclists were only required to perform one exercise test during the competition period (April-May).

EXERCISE TESTS

Each test was performed on a bicycle ergometer (Ergometrics 900; Ergo-line, Barcelona, Spain) following a ramp protocol until exhaustion. This protocol has been used in previous investigations performed in our laboratory on top level cyclists. ${ }^{2}{ }^{15-17}$ Starting at $0 \mathrm{~W}$, the workload was increased by $25 \mathrm{~W} / \mathrm{min}$, and pedalling cadence was kept constant at 70-90 $\mathrm{rev} / \mathrm{min}$. A pedal frequency meter was used by the subject to maintain this cadence. Each exercise test was terminated (a) voluntarily by the subject, $(b)$ when pedalling cadence could not be maintained at $70 \mathrm{rev} / \mathrm{min}$ (at least), or (c) when established criteria of test termination 


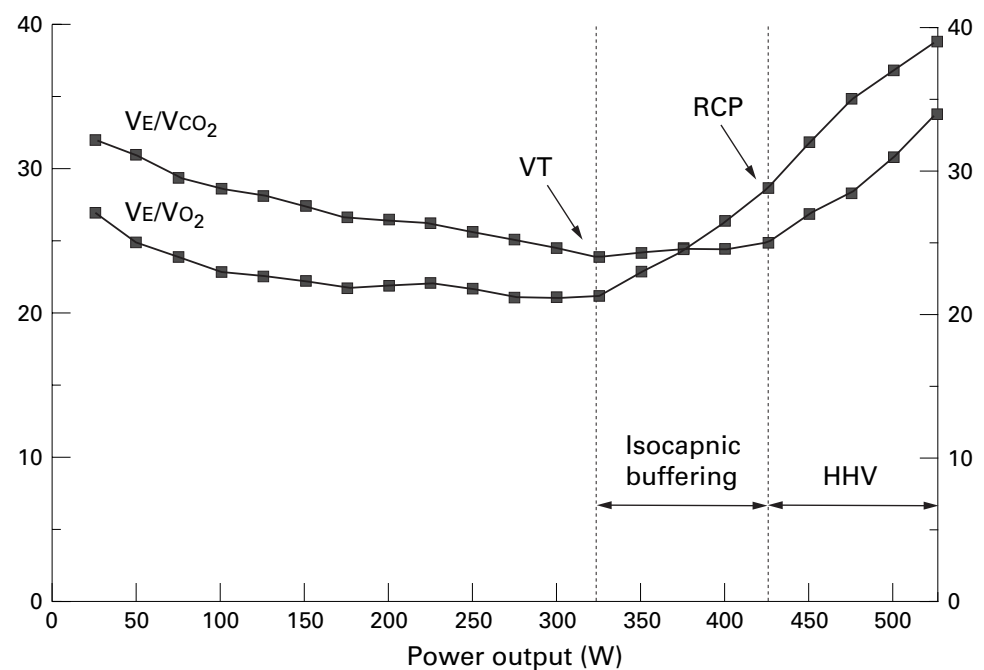

Figure 2 Determination of isocapnic buffering and hypocapnic hyperventilation (HHV) ranges $(W)$ in one subject. Mean values of both ventilatory equivalents for oxygen and carbon dioxide $\left(V_{E} / V_{O_{2}}\right.$ and $\left.V_{E} / V_{C O}\right)$ are plotted for each one minute interval. VT, Ventilatory threshold; RCP, respiratory compensation point.

Table 2 Maximal values of physiological variables in the professional and amateur cyclists studied

\begin{tabular}{|c|c|c|c|c|}
\hline \multirow[b]{2}{*}{ Group period } & \multicolumn{3}{|l|}{ Professional } & \multirow{2}{*}{$\begin{array}{l}\text { Amateur, } \\
\text { competition }\end{array}$} \\
\hline & Rest & Precompetition & Competition & \\
\hline $\mathrm{VO}_{2} \operatorname{MAX}$ & $73.2(6.1)$ & $74.8(4.5)$ & $74.9(6.1)$ & $75.2(4.9)$ \\
\hline VEMAX & $177.7(13.0)$ & $174.9(16.2)$ & $180.7(14.5)$ & $179.6(20.8)$ \\
\hline HR (beats/min) & $195(6)$ & $192(4)$ & $190(10)$ & $189(7)$ \\
\hline W & $504.0(32.9)$ & $508.5(25.5)$ & $496.0(34.9)$ & $425.4(33.6)^{\star}$ \\
\hline $\mathrm{W} / \mathrm{kg}$ & $7.1(0.5)$ & $7.2(0.4)$ & $7.3(0.5)$ & $6.3(0.5)^{\star}$ \\
\hline
\end{tabular}

Values are expressed as means (SD). $\mathrm{VO}_{2} \mathrm{MAX}$ is expressed in $\mathrm{ml} / \mathrm{kg} / \mathrm{min}$

${ }^{\star} \mathrm{p}<0.01$ compared with professional cyclists (competition period).

HR, heart rate.
DETERMINATION OF THE RANGE OF ISOCAPNIC BUFFERING AND HHV

The isocapnic buffering and $\mathrm{HHV}$ ranges were defined as: $\mathrm{VO}_{2}$, and W from VT to RCP, and $\mathrm{VO}_{2}$ and $\mathrm{W}$ from RCP to the end of exercise respectively. ${ }^{14}$ Figure 2 shows an example of isocapnic buffering/HHV range determination in one subject.

RELATIVE BUFFERING CAPACITY

A relative value for the buffering capacity (relFB) was determined as suggested by Röcker et al. ${ }^{8}$ RelFB was defined as the proportion of buffering within the performance up to the RCP, and calculated as the difference between performance (W or $\mathrm{W} / \mathrm{kg}$ ) at VT and that at RCP expressed as a percentage of the latter (equations 1 and 2):

RelFB $=\left(\left(\mathrm{W}_{\mathrm{RCP}}-\mathrm{W}_{\mathrm{VT}}\right) / \mathrm{W}_{\mathrm{RCP}}\right) \times 100$

RelFB $=\left(\left(\mathrm{W} / \mathrm{kg}_{\mathrm{RCP}}-\mathrm{W} / \mathrm{kg}_{\mathrm{VT}}\right) / \mathrm{W} /\right.$

$\left.\mathrm{kg}_{\mathrm{RCP}}\right) \times 100$

where $\mathrm{W}_{\mathrm{RCP}}$ (or $\mathrm{W} / \mathrm{kg}_{\mathrm{RCP}}$ ) and $\mathrm{W}_{\mathrm{RCP}}$ (or $\left.\mathrm{W} / \mathrm{kg}_{\mathrm{RCP}}\right)$ are power output at the RCP and VT respectively.

\section{STATISTICAL ANALYSIS}

A one way repeated measures analysis of variance was used to compare the physiological variables in professional cyclists during the three periods of study. When this test indicated a significant difference, the post hoc Scheffé test was applied to the data. Student's $t$ test for unpaired data was also used to compare physiological data corresponding to the competition period in amateur cyclists and professional cyclists. All values are reported as means (SD). The level of significance was set at 0.05 .

were met. ${ }^{18}$ During the test, subjects adopted the conventional (upright) cycling posture. Tests were performed under similar environmental conditions $\left(21-24^{\circ} \mathrm{C}, 45-55 \%\right.$ relative humidity). Heart rate (beats/min) was continuously monitored from modified 12 lead ECG tracings (EK56; Hellige, Freiburg, Germany). Gas exchange data were obtained using an automated breath by breath system (CPX; Medical Graphics, St Paul, Minnesota, USA). The instruments were calibrated before each test and the necessary environmental adjustments made. Ventilatory equivalents for oxygen and carbon dioxide $\left(\mathrm{VE} / \mathrm{VO}_{2}\right.$ and $\mathrm{VE} / \mathrm{VCO}_{2}$ respectively) were measured from $\mathrm{VO}_{2}, \mathrm{VCO}_{2}$, and $\mathrm{VE}$ data recorded during the tests.

DETERMINATION OF VT AND RCP

VT was determined using the criteria of an increase in $\mathrm{VE} / \mathrm{Vo}_{2}$ with no increase in $\mathrm{VE} / \mathrm{VCO}_{2}$ and the departure from linearity of $\mathrm{VE}^{19}$ whereas RCP was taken as that corresponding to an increase in both $\mathrm{VE} / \mathrm{VO}_{2}$ and $\mathrm{VE} / \mathrm{VCO}_{2}{ }^{19}$ VT and RCP were visually detected by two independent experienced observers. If there was disagreement, the opinion of a third investigator was sought. The selection of this non-mathematical method for detection of both VT and RCP during a cycle ergometer ramp protocol has previously been reported in several studies conducted in our laboratory with professional cyclists. ${ }^{2}{ }^{15-17}$

\section{Results}

MAXIMAL VALUES

Table 2 shows the maximal values of $\mathrm{VO}_{2}$, power output, $\mathrm{VE}$, and heart rate. No significant differences in mean $\mathrm{VO}_{2}$, power output, or heart rate were found for professional cyclists between the seasonal periods.

Maximal values of power output were significantly higher $(p<0.01)$ in professional cyclists than in amateur cyclists.

\section{VT AND RCP}

Table 3 gives the values for $\mathrm{VO}_{2}, \% \mathrm{VO}_{2} \mathrm{MAX}$, and power output at exercise intensities corresponding to VT and RCP. The only significant differences $(p<0.05)$ observed were between power outputs corresponding to VT recorded at rest and during competition and between power outputs corresponding to RCP at rest, compared with both precompetition and competition values in the professional cyclists.

Mean values of $\mathrm{VO}_{2}, \% \mathrm{VO}_{2} \mathrm{MAX}$, and power output corresponding to VT and RCP were significantly $(\mathrm{p}<0.01)$ higher in professional cyclists than amateur cyclists.

ISOCAPNIC BUFFERING AND HHV

Table 4 shows the mean values for isocapnic buffering and HHV ranges. There were no significant differences in the isocapnic buffering range recorded in each of the periods for the professional cyclists. In contrast, there was a 
Table 3 Physiological variables at the ventilatory threshold (VT) and respiratory compensation point (RCP) in the professional and amateur cyclists studied

\begin{tabular}{|c|c|c|c|c|}
\hline \multirow[b]{2}{*}{ Group period } & \multicolumn{3}{|l|}{ Professional } & \multirow{2}{*}{$\begin{array}{l}\text { Amateur, } \\
\text { competition }\end{array}$} \\
\hline & Rest & Precompetition & Competition & \\
\hline $\mathrm{VT}\left(\mathrm{VO}_{2}\right)$ & $52.6(6.9)$ & $54.9(3.8)$ & $55.2(4.2)$ & $45.8(6.3) \ddagger$ \\
\hline $\mathrm{VT}\left(\% \mathrm{VO}_{2} \mathrm{MAX}\right)$ & $71.7(5.0)$ & $71.9(6.2)$ & $73.7(4.5)$ & $60.6(6.8) \ddagger$ \\
\hline $\mathrm{VT}(\mathrm{W})$ & $320.0(29.1)^{\star}$ & $331.5(36.2)$ & $344.0(28.2)$ & $230.7(29.1) \ddagger$ \\
\hline VT (W/kg) & $4.5(0.4)^{\star}$ & $4.7(0.5)$ & $5.0(0.4)$ & $3.4(0.4) \ddagger$ \\
\hline $\operatorname{RCP}\left(\mathrm{VO}_{2}\right)$ & $64.8(6.7)$ & $65.4(3.8)$ & $67.4(5.2)$ & $61.3(7.9)$ \\
\hline $\mathrm{RCP}\left(\% \mathrm{VO}_{2} \mathrm{MAX}\right)$ & $88.3(3.1)$ & $86.5(3.4)$ & $90.0(3.3)$ & $81.4(5.8) \ddagger$ \\
\hline $\mathrm{RCP}(\mathrm{W})$ & $403.0(40.4) \dagger$ & $421.0(39.6)$ & $430.0(34.2)$ & $334.8(25.4) \ddagger$ \\
\hline $\mathrm{RCP}(\mathrm{W} / \mathrm{kg})$ & $5.7(0.6) \dagger$ & $6.0(0.6)$ & $6.3(0.5)$ & $5.0(0.4) \ddagger$ \\
\hline
\end{tabular}

Values are expressed as means (SD). $\mathrm{VO}_{2}$ is expressed in $\mathrm{ml} / \mathrm{kg} / \mathrm{min}$.

${ }^{\star} \mathrm{p}<0.05$ for rest $v$ competition periods in professional cyclists; $\dagger \mathrm{p}<0.05$ for rest $v$ both precompetition and competition periods in professional cyclists; $\neq \mathrm{p}<0.01$ for professional cyclists (competition period) $v$ amateur cyclists.

Table 4 Isocapnic buffering and hypocapnic hyperventilation (HHV) ranges in the professional and amateur cyclists studied

\begin{tabular}{|c|c|c|c|c|}
\hline & \multicolumn{3}{|l|}{ Professional } & \multirow{2}{*}{$\begin{array}{l}\text { Amateur, } \\
\text { competition }\end{array}$} \\
\hline & Rest & Precompetition & Competition & \\
\hline \multicolumn{5}{|c|}{ Isocapnic buffering } \\
\hline $\mathrm{Vo}_{2}$ & $12.8(4.3)$ & $10.9(3.6)$ & $12.2(2.6)$ & $15.6(6.8)$ \\
\hline $\mathrm{W}^{2}$ & $83.0(17.3)$ & $89.5(20.3)$ & $86.0(20.2)$ & $104.1(32.2)$ \\
\hline \multicolumn{5}{|l|}{$\mathrm{HHV}$} \\
\hline $\mathrm{VO}_{2}$ & $8.4(2.1)$ & $9.4(3.8)$ & $7.5(2.6)$ & $13.9(3.9) \dagger$ \\
\hline $\mathrm{W}^{2}$ & $101.0(19.6)$ & $87.5(27.9)^{\star}$ & $66.0(21.4)^{\star \star}$ & $90.6(25.8) \dagger$ \\
\hline
\end{tabular}

Values are expressed as means (SD). $\mathrm{VO}_{2}$ is expressed in $\mathrm{ml} / \mathrm{kg} / \mathrm{min}$.

${ }^{\star} \mathrm{p}<0.05,{ }^{\star \star} \mathrm{p}<0.01$ compared with the rest period in professional cyclists; $\mathrm{tp}<0.01$ compared with the competition period in professional cyclists.

significant reduction in the HHV range (expressed in $\mathrm{W}$ ) during both the competition $(\mathrm{p}<0.01)$ and precompetition periods $(\mathrm{p}<0.05)$ compared with the rest period.

Although no significant differences were detected in the isocapnic buffering range between professional and amateur cyclists, a longer HHV range $(\mathrm{p}<0.01)$ was observed in amateur cyclists (whether this was expressed in terms of $\mathrm{VO}_{2}$ or $\mathrm{W}$ ).

RELATIVE BUFFERING CAPACITY

No significant differences were found between professional cyclists throughout the study in mean values of relFB (expressed in either W or $\mathrm{W} / \mathrm{kg}$; fig 3). In contrast, amateur cyclists exhibited significantly higher values (in W or $\mathrm{W} / \mathrm{kg}$ ) than professional cyclists.

\section{Discussion}

The main finding of this investigation was the lack of change observed in the isocapnic buffering range of professional cyclists throughout the sports season, despite a considerable increase in training loads and the significant reduction in HHV range expressed in terms of power output. It was also shown that, of the variables related to both VT and RCP, isocapnic buffering/HHV ranges, and maximal variables commonly monitored in athletes during a sports season (power output, $\% \mathrm{VO}_{2} \mathrm{MAX}$, etc), power output (W and $\mathrm{W} / \mathrm{kg}$ ) best reflected the fitness level of the cyclists.

The maximal variable values obtained here are similar to those previously recorded for professional and/or amateur cyclists in our laboratory. ${ }^{2}{ }^{15-17}$ Although some authors have shown that the $\mathrm{VO}_{2} \mathrm{MAX}$ of elite cyclists increases slightly during the season, ${ }^{20}$ our data are in line with those of most previous
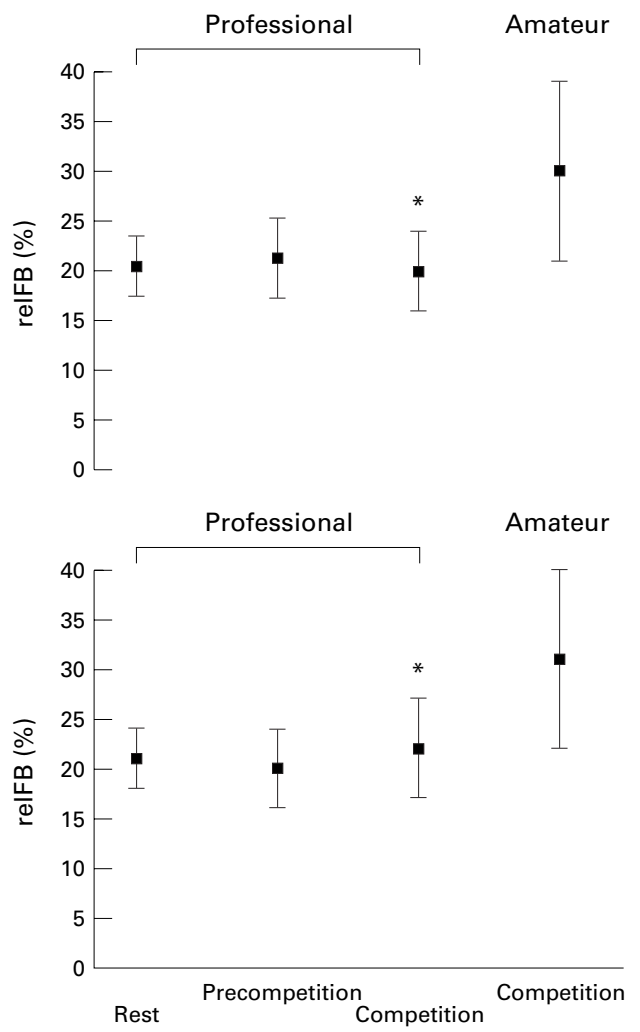

Figure 3 Relative buffering capacity (RelFB) in professional and amateur cyclists. Performance (at both the ventilatory threshold and the respiratory compensation point) is expressed in W in the top panel and in W/kg in the bottom panel. ${ }^{*} p<0.05$ for professional cyclists $v$ amateur cyclists during the competition period.

studies which show no significant effects of training intervention on $\mathrm{VO}_{2} \mathrm{MAX}$ in well trained athletes. ${ }^{5-7}$ Further, we detected no difference in maximal power output throughout the season in the professional cyclists, although the values recorded in the competition stages were significantly higher than in the amateur cyclists. This is in agreement with our previous research. ${ }^{2}$ On the other hand, our findings also confirm that, although high levels of $\mathrm{VO}_{2} \mathrm{MAX}$ are needed for top level competition in cycling, one of the most significant characteristics of professional cyclists is their capacity to perform at high workloads ( $90 \%$ of $\left.\mathrm{VO}_{2} \mathrm{MAX}\right)$ during long periods of time ( 60 minutes)..$^{2-4}$ The high values of RCP observed in the professional cyclists, and the corresponding reduction in the $\mathrm{HHV}$ range as the season advanced, could indeed be interpreted as a greater ability to work at high intensities before lactic acid accumulation occurs in the blood.

The values of all the variables related to VT and RCP were similar to those previously obtained by us for professional and amateur cyclists. ${ }^{2}$ Both VT and RCP, expressed as $\mathrm{VO}_{2}$, $\% \mathrm{VO}_{2} \mathrm{MAX}, \mathrm{W}$, or $\mathrm{W} / \mathrm{kg}$, were higher in the professional cyclists than in the amateurs, reflecting a higher aerobic endurance in the former. The mean power output values corresponding to VT and RCP observed in the professional cyclists were significantly higher during the competition period with no significant change (despite a tendency to increase) 
when the intensity of exercise was expressed as $\mathrm{VO}_{2}$ or $\% \mathrm{VO}_{2} \mathrm{MAX}$.

Changes in the maximal variables and in VT and RCP conditioned the isocapnic buffering and HHV ranges during the season in the professional cyclists. Whereas the isocapnic buffering range remained unchanged throughout the season (causing the similar rightward shift in VT and RCP), the HHV range was reduced significantly during the competition period when expressed as power output but not as $\mathrm{VO}_{2}$. The fact that power output was the major discriminator in this period of the season may be explained by: $(a)$ the fact that the relation between $\mathrm{VO}_{2}$ and workload is not strictly linear especially at high exercise intensity where lactic acidosis occurs ${ }^{22}$; $(b)$ the improvement in cycling efficiency associated with endurance training. The present results show a similar shift in VT and RCP in professional cyclists throughout the season, reflecting both a constant isocapnic buffering range and relFB index. In contrast, Oshima et $a l^{14}$ observed that the increase in the RCP is larger than that of VT after high intensity endurance training in runners. Similarly, Röcker et $a l^{\beta}$ reported a longer isocapnic buffering phase in elite $400 \mathrm{~m}$ runners than in endurance trained (non-elite) runners or sedentary subjects. This may suggest that intense training sessions involving anaerobic metabolism (such as those performed by $400 \mathrm{~m}$ runners) improve the buffering capacity - that is, the shift in RCP towards higher workouts in these athletes compared with endurance athletes - and not the oxidative capacity - that is, workload at which VT occurs - consequently extending the isocapnic buffering range. It appears, however, that the type of endurance training performed by professional cyclists-that is, 30000-35000 $\mathrm{km}$ a year during which aerobic metabolism is principally involved - induces a similar shift in both VT and RCP.

Acccording to Oshima and coworkers ${ }^{14}$, the shift in RCP towards higher intensities could reflect both an increase in aerobic endurance and an exercise induced improvement in bicarbonate buffering capacity. Our findings, however, do not corroborate their hypothesis because average relFB was significantly lower in the professional cyclists than in the amateurs. The reasons for such a difference in relative buffering capacity between the two groups are not apparent, as relative training intensity was comparable in the two groups. Thus the increase in bicarbonate buffering found by other researchers ${ }^{723}$ in response to hard endurance training of long duration was not confirmed in our group of professional cyclists. A genetically determined difference in muscle fibre distribution - that is, higher content of fast twitch fibres-may partly explain the higher buffering capacity of amateur cyclists. ${ }^{25}$ It could be also hypothesised that the muscle content of buffer active proteins is higher in the latter. ${ }^{25}$ Thus, one adaptation to professional cycling (compared with amateur categories) may be a decrease in buffering capacity (at least in workloads between VT and RCP), which seems to be exchanged for a higher oxidative capacity. Some modification in fibre type (from slow to fast twitch) in the professional cyclists could also have been involved. The aforementioned adaptations may occur in professional cyclists after years of high volume endurance training. Although anaerobic metabolism is sometimes involved-that is, during some decisive parts of the races-average exercise intensity is mostly low to moderate (below VT) in professional cycling. ${ }^{3}$

In conclusion, it would appear that there is an improvement in aerobic capacity with no concomitant increase in relative buffering capacity during defined periods of a complete season in professional cyclists. Both the fact that VT and RCP show a similar shift and that $\mathrm{VO}_{2} \mathrm{MAX}$ does not change show that the isocapnic buffering range does not change over the season, leading, in contrast, to a shortening of the HHV phase. Further, the results suggest that expression of the maximal and submaximal physiological data as power output (W or $\mathrm{W} / \mathrm{kg}$ ) best reflects an improvement in the fitness level of these athletes.

The authors acknowledge Ana Burton for the translation of the manuscript. This study was financed as the result of a formal agreement between the Asociación Deportiva Banesto and the Complutense University of Madrid.

The experiments of this study comply with the current laws of the country (Spain) in which the experiments were performed.

1 Coyle EF, Feltner ME, Kautz SA, et al. Physiological and biomechanical factors associated with elite endurance cycling performance. Med Sci Sports Exerc 1991;23:93-107.

2 Lucía A, Pardo J, Durántez A, et al. Physiological differences Lucía A, Pardo J, Durántez A, et al. Physiological differences
between professional and elite road cyclists. Int $\mathcal{F}$ Sports Med 1998;19:342-8.

3 Lucía A, Hoyos J, Carvajal A, et al. Heart response to professional road cycling: the Tour of France. Int $\mathcal{F}$ Sports Med 1999;20:167-72.

4 Padilla A, Mujika I, Cuesta G, et al. Level ground and uphill cycling ability in professional road cycling. Med Sci Sports Exerc 1999;31:878-85.

5 Sjodin B, Jacobs I, Svedenhag J. Changes in onset of blood actate accumulation (OBLA) and muscles enzymes after training at OBLA. Eur f Appl Physiol 1982;49:45-57.

6 Costill DL, Flynn MG, Kirman JP, et al. Effects of repeated days of intensified training on muscle glycogen and swimming performance. Med Sci Sports Exerc 1988;20: 249-54

7 Weston AR, Myburgh KH, Lindsay FH, et al. Skeletal muscle buffering capacity and endurance performance after high-intensity interval training by well trained cyclists. Eur f Appl Physiol 1997;75:7-13.

8 Röcker K, Striegel H, Freund T, et al. Relative functional buffering capacity in 400-meter runners, long-distance runners and untrained individuals. Eur F Appl Physiol 1994; 68:430-4.

9 Beaver WL, Wasserman K, Whipp BJ. Bicarbonate buffering of lactic acid generated during exercise. $\mathcal{F}$ Appl Physiol 1986;60:472-8.

10 Wasserman K, Beaver WL, Whipp BJ. Gas exchange theory and the lactic acidosis (anaerobic) threshold. Circulation 1990;81 (suppl II): 14-30.

11 Lopategui E, Pérez HR, Smith TK, et al. The anaerobic threshold of elite and novice cyclists. F Sports Med 1986;26: 123-7.

12 Coyle EF, Coggan AR, Hopper MK, et al. Determinants of endurance in well-trained cyclists. $\mathscr{f}$ Appl Physiol 1988;64: 2622-30.

13 Oshima Y, Miyamoto T, Tanaka S, et al. Relationship between isocapnic buffering and maximal aerobic capacity in athletes. Eur F Appl Physiol 1997;76:409-14.

14 Oshima Y, Tanaka S, Miyamoto T, et al. Effects of endurance training above the anaerobic threshold on isocapnic buffering phase during incremental exercise in middle-distance runners. Fapanese fournal of Physical Fitness and Sports Medicine 1998;47:43-52.

15 Chicharro JL, Carvajal A, Pardo J, et al. Physiological parameters determined at OBLA vs. a fixed heart rate of 175 beats. $\mathrm{min}^{-1}$ in an incremental test performed by amateur and professional cyclists. Fpn F Physiol 1999;9:63-9.

16 Lucía A, Carvajal A, Alfonso A, et al. Breathing pattern of high competitive cyclists during incremental exercise. Eur $\mathcal{F}$ Appl Physiol 1999;79:512-21.

17 Lucía A, Sánchez O, Carvajal A, et al. Analysis of the aerobic-anaerobic transition in elite cyclists during incremental exercise with the use of EMG. Br f Sports Med 1999;33:178-85. 
18 American College of Sports Medicine (ACSM). Guidelines for exercise testing and prescription. 6th ed. Philadelphia: Lea \& Febiger, 1986

19 Davis JA. Anaerobic threshold: a review of the concept and directions for future research. Med Sci Sports Exerc 1985;17:6-18.

20 Fagard R, Aubert A, Lysens R, et al. Noninvasive assessment of seasonal variations in cardiac structure and function in cyclists. Circulation 1983;67:896-901.

21 White JA, Quinn G, Al-Dawalibi M, et al. Seasonal changes in cyclists' performance. Part 1. The British road race squad. Br $\mathcal{F}$ Sports Med 1982;16:4-12.
22 Poole DC, Schaffartzik W, Knight DR, et al. Contribution of exercising legs to the slow component of oxygen uptake exercising legs to the slow component of oxygen
kinetics in humans. F Appl Physiol 1991;71:1245-53.

23 Bell GJ, Wenger HA. The effect of one-legged sprint training on intramuscular $\mathrm{pH}$ and nonbicarbonate buffering capacity. Eur F Appl Physiol 1988;58:158-64.

24 Hirakoba K, Maruyama A, Inaki M, et al. Effect of endurance training on excessive $\mathrm{CO}_{2}$ expiration due to lactate production in exercise. Eur f A ppl Physiol 1992;64:73-7. 25 Grossie J, Collins C, Julian C. Bicarbonate and fast-twitch muscle: evidence for a major role in $\mathrm{pH}$ regulation. $f$ Membr Biol 1988;105:265-72.

\section{Take home message}

No change is observed in the isocapnic buffering range of professional cyclists throughout a season, despite a considerable increase in training loads and an appreciable reduction in HHV range. Of the physiological variables commonly monitored during exercise testing, power output (W or W/kg) best reflects the fitness level of highly trained cyclists.

\section{Reflections on production of the written word}

Many of my early publications were handwritten, and an ink ribbon typewriter was high-tech for me!

I have reflected that, when I began school in the late 1950 s, using a stick pen (no fancy quill) and ink well was supposed to enhance our writing skills. Shakespeare would have been right at home even after 400 years! Fortunately, my father was a police officer and required a typewriter for his reports. It must have weighed 30 pounds in order to remain still while the carriage returned, etc. When I was at graduate school in the US during the $1970 \mathrm{~s}$, term papers had to be typewritten. I was pleased to discover Erasable Bond paper which made mistakes disappear.

Upon returning to England, I purchased a portable which had a ribbon containing a cover up material on its lower half.

By the time I returned to the States in the 1980s, IBM had developed the electric golfball series. Carbon ribbons made the finished article appear to have been typeset! Could it get any better than this? Apparently, yes, and in short order we advanced to electronic typewriters, word processors, and computers - a period of merely 40 years. We now, quite literally, have the world at our fingertips - within a scant four years.

What's next? We are already embracing the replacement of dexterity with voice recognition. Then we attach our brains directly to the computer and upload, or download, in whichever direction? No need for books, or finger dexterity.

This would certainly answer the old chestnut about the redundancy of information during medical education: "By the time you graduate from medical school, half of what you learned will have become obsolete. If we only knew which half ...”.

DAVID PONSONBY Dormaley, Fore Street, Cornwall TR20 9HD 